\title{
Adequacy of macro and micronutrients in infants and young children's diets in Zanzibar, Tanzania
}

\author{
Joyce Kinabo ${ }^{1}$, Peter Mamiro ${ }^{1}$, Akwilina Mwanri ${ }^{1}$, Nyamizi Bundala ${ }^{1}$, Kissa Kulwa ${ }^{1}$, Janeth Picado ${ }^{2}$, \\ Julius Ntwenya ${ }^{3}$, Aneth Nombo ${ }^{4}$, Rehema Mzimbiri ${ }^{4}$, Fatma Ally ${ }^{5}$, Asha Salmini ${ }^{5}$, Abuu Juma ${ }^{5}$, \\ Elizabeth Macha ${ }^{6}$, Edith Cheung ${ }^{7}$, John Msuya ${ }^{1}$
}

1. Department of Food Technology, Nutrition and Consumer Sciences, Sokoine University of Agriculture, P. O. Box 3006, Morogoro.

2. Apartado LC-13 Managua, Nicaragua.

3. School of Nursing and Public Health, Department of Public Health, College of Health Sciences University of Dodoma, P. O. Box 259 Dodoma, Tanzania.

4. Tanzania Food and Nutrition Center, Barrack Obama Avenue, P.O. Box 977,Dar-es-Salaam, Tanzania.

5. Ministry of Health Zanzibar.

6. UNICEF P. O. Box 4076, Tanzania.

7. UNICEF 3 UN Plaza New York, NY, 10016 USA.

\begin{abstract}
Background: A study was conducted in Zanzibar using ProPAN software to assess nutrient adequacy of foods given to infants and children aged 6-23 months old in Zanzibar.

Methodology: The 24-hr dietary recall method embedded in ProPAN software was used to determine the adequacy of energy, protein, iron, calcium, zinc and vitamin A in foods consumed by children. Sample of 200 mothers/caretakers with children aged 6-23 months were interviewed.

Results: Most frequent foods given to infants and children were tea, bread, white rice and fish. Key nutrients such as iron, zinc and vitamin A were below the recommended levels except for vitamin $\mathrm{C}$ from the diets consumed by children aged 11-23 months. Energy and protein were considered to be adequate as more than $90 \%$ of the children received enough of these nutrients. Mean age of introduction of complementary foods was four months.

Conclusion: Children diets were limited in fruits and vegetables that caused micronutrients of nutritional importance such as iron, zinc and vitamin A to be supplied below recommended level. Equally, fat intake was below recommended level. Nutrition education on appropriate complementary foods should be given to caregivers. Promotion of consumption of diversified diets and locally available nutrient dense foods should be emphasized so as to achieve adequate intake of nutrients to infants and young children.
\end{abstract}

Keywords: ProPAN, children, nutrient adequacy, Zanzibar.

DOI: https://dx.doi.org/10.4314/ahs.v19i4.28

Cite as: Kinabo J, Mamiro P, Mwanri A Bundala N, Kulwa K, Picado J, Ntwenya J, Nombo A, Mzimbiri R, Ally F, Salmini A, Juma A, Macha E, Cheung E, Msuya J. Adequacy of macro and micronutrients in infants and young children's diets in Zanzibar, Tanzania. Afri Health Sci.2019;19(4):3063-3077. https://dx.doi.org/10.4314/abs.v19i4.28

\section{Corresponding author:}

Peter Mamiro, Department of Food Technology,

Nutrition and Consumer Sciences,

Sokoine University of Agriculture,

P. O. Box 3006, Morogoro.

Email: petermamiro@yahoo.com

\section{Background}

Good nutrition management plays a central role in alleviating food and nutrition insecurity and ill health of children in developing countries ${ }^{1-3}$. Infant and young child feeding is a key area to improve child survival and promote healthy growth and development ${ }^{4}$. It is now generally accepted that the first 2 years of a child's life is particularly important, as optimum nutrition during this

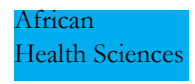

(C) 2019 Kinabo et al. Licensee African Health Sciences. This is an Open Access article distributed under the terms of the Creative commons Attribution License (https://creativecommons.org/licenses/BY/4.0), which permits unrestricted use, distribution, and reproduction in any medium, provided the original work is properly cited. 
period lowers disease and reduce death risks, and fosters overall better development ${ }^{5}$. Inadequate breastfeeding and especially sub-optimal exclusive breastfeeding during the first half-year of life compounded by inappropriate complementary feeding - is important risk factors for infant malnutrition ${ }^{6,7}$.

Globally it is estimated that under-nutrition is responsible, directly or indirectly, for at least $35 \%$ of deaths in children less than five years of age ${ }^{8}$. Under-nutrition is also a major cause of inability and disability preventing children who survive from reaching their full development potential ${ }^{9}$. Child feeding practices are multidimensional and they change rapidly within short age-intervals in the first years of life. Unlike exclusive breastfeeding, which can be summarized in a single indicator, the measurement of feeding practices in children aged 6 months and older involves assessing various dimensions of feeding simultaneously. These dimensions include continued breastfeeding, appropriate timing of introduction of complementary foods, and optimum quantity and quality of the foods consumed. Adequate complementary feeding of children from 6 months onwards is particularly important for growth and development and the prevention of under-nutrition. Childhood under-nutrition remains a major health problem in resource-poor settings. In 2011, over a quarter of children less than five years of age in low-income countries, or 165 million children under five years of age, were stunted (low height-for-age), and large proportions were also deficient in one or more micronutrients ${ }^{10}$. That means they required the addition of nutrient dense, high quality foods in sufficient quantities in their diet along with continued breastfeeding. There is evidence that complementary feeding practices are generally poor in most developing countries, meaning that many children continue to be vulnerable to largely irreversible outcomes such as stunting and poor cognitive development, as well as to significantly increased risks of infectious diseases like diarrhoea and pneumonia ${ }^{1,2,11}$. Even in resource poor settings, improved feeding practices can lead to improved intakes of energy and nutrients, leading to better nutritional status ${ }^{12,13}$.

ProPAN is a free tool developed by the Pan American Health Organization (PAHO) and UNICEF for ministries of health and non-governmental organization (NGOs) to improve IYCF practices according to WHO and UNICEF ideal practices and growth standards. It is a comprehensive tool for program planners wishing to improve Infant and Young Child Nutrition that can be adapted to local settings ${ }^{14}$. A software package is included to aid in the analysis of the ProPAN data. It serves to identify the key problem nutrient and the relative importance and cost of local foods as sources of these nutrients. The ProPAN package was considered better than the other tools because it leads to a comprehensive formative research and assessment that will yield valuable information about the local context and nutrition status that will guide planning of interventions on child feeding practices. Another advantage of ProPAN is that it allows flexibility to fit into local context and it is designed to identify nutrition problems among children under two years of age and pregnant or lactating women, the causes of these problems, and recommendations for programmatic interventions to improve child nutrition ${ }^{14,15}$. This study aimed at investigating adequacy of nutrients in foods given to infants and young children in Zanzibar, Tanzania using ProPAN tool with the view to develop interventions that can be used to address the situation.

\section{Methodology}

The study was carried out in Zanzibar- Unguja Island involving all 6 districts whereby 36 Shehias and 200 households were randomly selected proportional to size. A total of 200 mothers/caretakers who had children aged 6-23 months were involved in the survey providing information regarding food intake of their children. Prevalence of stunting (low height-for-age) in Unguja (26.7\%) was used to determine sample size as the project aim to minimize malnutrition in Zanzibar.

Sample size was calculated from the following Fisher's formula:

$$
n=\frac{Z^{2} * p * q}{d^{2}}
$$

Where-by: $\mathrm{n}=$ desired minimum sample size; $\mathrm{Z}=$ the standard normal deviate corresponding to $95 \%$ Confidence Interval; $\mathrm{p}=$ the proportion of an indicator measured (In this case prevalence of stunting); $\mathrm{q}=1-\mathrm{p}$; $\mathrm{d}$ $=$ degree of accuracy or desired precision. Taking the prevalence of stunting in Zanzibar as $26.7 \%$ or $0.267, \mathrm{Z}$ statistic corresponding to $95 \%$ confidence interval for a two-tailed test as 1.96, and degree of accuracy at 0.05 , the sample size was:

$$
n=\frac{1.96^{2} * 0.267 * 0.733}{0.05^{2}} \quad \mathrm{n}=300
$$

The computed sample size of 300 households was based 
on the prevalence of stunting of children below five years of age. However, in the current study the target population is children below two years of age, which was estimated to be $60 \%$ of the total population of children below five years of age. Therefore a purposive sample of 180 households with children below 2 years was required to participate in the study. An attrition rate of $20 \%$ was added to take care of the non-response or those who would decline to participate in the study. In this regard, a total sample size was 216 as explained elsewhere ${ }^{15}$. There were 16 households whose 24 hour dietary recall information was not complete and hence remaining with 200 households.

The 24-hour Dietary Recall method embedded in ProPAN software was used to determine the adequacy of energy, protein, iron, calcium, zinc and vitamin A in foods consumed by children in Zanzibar. Promotion of Child Feeding (ProPAN) tool is software designed to analyse quantitative data on infant and young child nutrition and feeding practices using tailor made data collection instruments. This software also gives a list of key foods commonly used for complementary feeding for infants and children ${ }^{14}$.

Specific forms were used to collect information about foods consumed in the past 24 hours, which included how foods were prepared, ingredients used including quantities, texture of meals, number of feedings and how the children were fed. Mothers were asked to provide information on the fluids, foods and preparations given to infants and children and show the quantities consumed by their children using household utensils (e.g. spoons, cups, bowls). In ProPAN language 'foods' refers to any edible animal or vegetable source, which include both industrialized ready-to-eat foods, those consumed raw e.g. apple, banana, lettuce, corn flakes, sweet bread, milk and cola beverages. Preparations include mixture of various foods in one dish e.g. rice and chicken soup mixed with vegetables; spaghetti mixed with beans and meat stew. Visual aids such as fresh foods and common household utensils were used to assist mothers and researchers to accurately measure and report portion sizes of the children food intake. The volumes were converted using standard measuring cups and spoons. Foods commonly consumed by infants and children in Unguja were prepared, measured using household measures and the volumes were weighed using a digital food weighing scale (CAMRY Model EK3651) to determine densities, edible portions and raw to cooked factors. For food preparations, recipe descriptions were documented from the mothers and used to calculate the nutrient composition. The amount of each ingredient in the food preparation was estimated from the portion consumed by the child as a fraction of the amount prepared. In cases where recipe information was not available, data for an average recipe was obtained from the Tanzania Food Composition Tables ${ }^{16}$. Interviews were carried out in participating homes to assist easy recall of foods consumed and calibration of family utensils using kitchen food scales.Analyses of energy and nutrient density of foods, nutrient intake, adequacy, and proportion of children with intakes below the recommended values, were determined using the ProPAN software $^{14}$.

\section{Permission and ethical considerations}

Permission and ethical clearance was requested from Zanzibar Medical Research Ethical Committee (ZAMREC) and granted vide letter with reference: ZAMREC/0002/ SEPT/012. The research protocol was explained to administrative officials of the district and selected Shehias. Parents of eligible children were informed of the objectives and activities of the research. Briefly, it was explained that participation to the study was voluntary and that they may cease to participate at any time if they so desire. Parents who agreed to participate provided verbal informed consent. Mothers who reported that their children were ill or malnourished, identified by field survey team during the course of the study were advised to report to the health facilities where they usually receive standard treatment and or rehabilitation.

\section{Results}

Information from a total of 200 children was collected from their caregivers during the 24 hour dietary recall interviews. The mean age of the infants and children was $13.5 \pm 4.7$ months whereas the mean age of infants who were $6-11$ months old was $8.3 \pm 1.7$ months and that of children of age between $12-23$ months was $16.3 \pm 3.1$ months (Table 1). 
Table 1: Age characteristics of children who were seen during 24 hour dietary recall

\begin{tabular}{lllll}
\hline Description & N & Mean & Variance & Std Dev \\
\hline Age of children & & & & \\
Child's age in months reported & 200 & 13.5 & 22.2 & 4.7 \\
Child's age in months, calculated & 200 & 13.5 & 22.2 & 4.7 \\
Age of breastfed children in months & 173 & 12.9 & 20.4 & 4.5 \\
Age of non-breastfed children in months & 27 & 17.0 & 19.7 & 4.4 \\
Age of children 6-11months category & 74 & 8.3 & 2.9 & 1.7 \\
Age of children 12-23 months category & 126 & 16.3 & 9.9 & 3.1 \\
\hline
\end{tabular}

The proportion of female children was $54 \%$ of all the children seen and that of male children was $46 \%$. On the other hand for the age group $6-11$ months, $60 \%$ were females and $40 \%$ were males. Similarly, for the age group $12-23$ months, $51 \%$ were females and $49 \%$ were males.
Most of the children (79\%) seen during the day of the survey were healthy as reported by the mothers (Table 2). However, the proportion varied between age groups. Infants of age between $6-11$ months had a lower proportion of sick children (17\%) compared to children in the age category of $12-23$ months, (24\%).

Table 2: Breast feeding and other characteristics of children who were seen during 24 hour dietary recall

\begin{tabular}{llll}
\hline & $\mathbf{N}$ & $\mathbf{\%}$ & $\mathbf{9 5 \%} \mathbf{C I}$ \\
\hline Breastfeeding status of children & & & \\
Breastfed & 173 & 86.5 & $81.0-90.9$ \\
Non-breastfed & 27 & 13.5 & $9.1-19.0$ \\
Total & $\mathbf{2 0 0}$ & $\mathbf{1 0 0}$ & \\
Sex of children & & & \\
Females & 108 & 54.0 & $46.8-61.1$ \\
Males & 92 & 46.0 & $38.9-53.2$ \\
Total & $\mathbf{2 0 0}$ & $\mathbf{1 0 0 . 0}$ & \\
Health status of children & & & \\
Children healthy & 157 & 78.5 & $72.2-84.0$ \\
Children sick & 43 & 21.5 & $16.0-27.8$ \\
Total & $\mathbf{2 0 0}$ & $\mathbf{1 0 0 . 0}$ & \\
The day for the survey & & & \\
Holiday or celebration & 9 & 4.5 & $2.1-8.4$ \\
No holiday or celebration & 191 & 95.5 & $91.6-97.9$ \\
Total & $\mathbf{2 0 0}$ & $\mathbf{1 0 0 . 0}$ & \\
\hline
\end{tabular}


About $14 \%$ of all the children were not breastfed during the 24 hour recall period and $86 \%$ were breastfed during this period (Table 2). Of those who were breast fed, $56 \%$ were males and $44 \%$ were females. For the non-breast fed children, $45 \%$ were males and $56 \%$ females. In addition, $85 \%$ of the children who were breastfed were healthy compared to $78 \%$ of those who were not breastfed. Twenty three percent of children who were not breast fed during the 24 hours were sick compared to only 15\% of the breast fed children. About $5 \%$ of the caregivers indicated that the day of the survey was a celebration for the household.

\section{Energy and nutrient density of diet}

Mean energy and nutrient density of total diet consumed by surveyed children in the previous 24 hours is presented in Table 3 and is compared to desired nutrient density of complementary foods. Mean energy density was slightly higher than the desired minimum levels. Mean protein density of diet was more than four times that of desired protein density. Similarly, mean vitamin $C$ density of diets was higher in 6-11 months age category but slightly lower for 12-23 months children. Frequent feeding of children with tea and bread could have contributed to provision of energy. Consumption of foods and preparations rich in protein could have contributed to higher density of this nutrient. Protein-dense meals which were highly consumed by the children included stews based on fish and kidney beans. The survey was conducted during mango season and most mothers admitted to have given their children juice squeezed from mangoes, which might have contributed to higher vitamin $\mathrm{C}$ density.

Table 3: Mean nutrient density of total diet consumed by surveyed children

\begin{tabular}{|c|c|c|c|c|c|c|}
\hline \multirow{2}{*}{\multicolumn{2}{|c|}{ Nutrient density of total diet }} & \multicolumn{2}{|c|}{$\begin{array}{l}\text { Desired nutrient density of } \\
\text { Complementary Foods }\end{array}$} & \multirow{2}{*}{$\begin{array}{r}\text { Mean } \\
\text { Intake }\end{array}$} & \multirow{2}{*}{ Variance } & \multirow{2}{*}{$\begin{array}{l}\text { Standard } \\
\text { deviation }\end{array}$} \\
\hline & & $\begin{array}{l}\text { Children } \\
\text { 6-11 months }\end{array}$ & $\begin{array}{l}\text { Children } \\
\text { 12-23 months }\end{array}$ & & & \\
\hline \multicolumn{2}{|c|}{ Energy density (kcal/g) } & $0.44-0.77$ & $0.74-0.98$ & 1.7 & 0.011 & 0.105 \\
\hline \multicolumn{2}{|c|}{ Protein density (g/100 kcal) } & 0.7 & 0.7 & 3.0 & 0.032 & 0.178 \\
\hline \multirow{2}{*}{$\begin{array}{l}\text { Iron density (mg/100 } \\
\text { kcal) }\end{array}$} & Low bioavailability & $4.6-7.7$ & 1.6 & \multirow[b]{2}{*}{0.5} & \multirow[b]{2}{*}{0.002} & \multirow[b]{2}{*}{0.044} \\
\hline & $\begin{array}{l}\text { Medium } \\
\text { bioavailability }\end{array}$ & $2.4-4.0$ & 0.8 & & & \\
\hline \multicolumn{2}{|c|}{ Zinc density (mg/100 kcal) } & $0.5-0.8$ & 0.3 & 0.3 & 0.000 & 0.021 \\
\hline \multicolumn{2}{|c|}{ Vitamin A (mcg RAE/100 kcal) } & $5-9$ & 17 & 0.0 & 0.036 & 0.191 \\
\hline \multicolumn{2}{|c|}{ Vitamin C density (mg/100 kcal) } & 0 & 1.1 & 0.8 & 0.655 & 0.809 \\
\hline \multicolumn{2}{|c|}{ Calcium density (mg/100 kcal) } & $78-125$ & 26 & 7.5 & 14.854 & 3.854 \\
\hline
\end{tabular}


Mean iron density of diets, assuming low or medium bioavailability, was lower than the desired density from complementary foods. The diets were insufficient to meet iron needs especially of younger children 6-11 months of age whose rapid growth and development necessitates increased requirements. Low consumption of iron-dense foods that are highly bioavailable (e.g. beef, chicken, liver and other organ meats) could be the reason of the low iron dietary density. Since iron absorption is interfered in the gut by presence of anti-nutritional factors (e.g. phytic acid and polyphenols) mostly found in plant-based foods, iron density of the diet would need to be addressed alongside improvement of its bioavailability.

Mean zinc density of diet for younger children (6-11 months) was lower than the desired density of complementary foods; however the density level $(0.3 \mathrm{mg} / 100$ kcal) for older children (12-23 months) appeared to be similar to the desired value of $0.3 \mathrm{mg} / 100 \mathrm{kcal}$. Because foods that supply zinc also supply iron and bioavailability of both nutrients are affected by same anti-nutritional factors, low consumption of highly bioavailable zincdense foods is likely to be the cause of low zinc density. Less frequently consumed foods such as beef, chicken, organ meats, legumes, oilseeds, and green leafy vegetables, are among those which are zinc-dense or can promote zinc absorption. Similarly, mean calcium density of diet was lower than the desired density from complementary foods. Calcium is highly supplied from animal milk and milk products (e.g. yoghurt, cheese, tea with milk), fish, especially those that are dried or can be eaten with bones, legumes, green leafy vegetables, and millets ${ }^{17}$. Among these, fish-based stews were the only commonly consumed meals and children were offered the sauce and not the flesh.
Mean vitamin A density of diet was lower than the desired density from complementary foods (5-9 mcg RAE/100 $\mathrm{kcal}$ for children 6-11 months and $17 \mathrm{mcg}$ RAE/100 kcal for children 12-23 months), and the current diets are insufficient to meet the needs of younger and older children. The vitamin A-dense foods reported from children's diet were amaranth leaves relish, asparagus, yellow maize flour, and popcorn. Less than 6 children were reported to have consumed these foods or meals made from them.

\section{Energy and nutrient density of the mostly consumed foods and preparations}

The foods that were most frequently consumed by the study children varied in energy density with a range from 0.2 to $3.2 \mathrm{kcal} / \mathrm{g}$ (Table 4$)$. African doughnut $(3.2 \mathrm{kcal} / \mathrm{g}$ ) and white bread $(2.7 \mathrm{kcal} / \mathrm{g})$ had the highest energy density while black tea with sugar was among the lowest in energy $(0.4 \mathrm{kcal} / \mathrm{g})$. Fish was the main source of protein, which was prepared in different ways such as fish relish with coconut milk, fresh fish stew or small dried fish (sardines) relish with coconut milk. Among the plant foods consumed, wheat porridge had the highest protein density $(7.0 \mathrm{~g} / 100 \mathrm{kcal})$. Kidney beans were the main source of iron $(2.5 \mathrm{mg} / 100 \mathrm{Kcal})$ and zinc $(1.3 \mathrm{mg} / 100 \mathrm{kcal})$. Vitamin $C$ density ranged from none in black tea to 58.0 $\mathrm{mg} / 100 \mathrm{kcal}$ in mixed fruit juice. Other good sources of vitamin $\mathrm{C}$ were relish made from sweet potato leaves and amaranth leaves. It was observed that in most cases, the leaves were boiled for long time (20-30 minutes); sometimes excess water was drained before addition of coconut milk. Amaranth leaves were the only source of vitamin A with about $68 \mu \mathrm{g}$ Retinol Activity Equivalent/100 kcal. Calcium density ranged from 0.3 to $197.0 \mathrm{mg} / 100 \mathrm{k}-$ cal in tea without milk with sugar and fish relish with coconut milk, respectively. Another good source of calcium was whole milk which contained about $192 \mathrm{mg} / 100 \mathrm{kcal}$. 
Table 4: Energy and nutrient density of most frequently consumed foods*

\begin{tabular}{|c|c|c|c|c|c|c|c|}
\hline Food name & $\begin{array}{l}\text { Energy } \\
\text { density } \\
\text { (Kcal/g) }\end{array}$ & $\begin{array}{l}\text { Protein } \\
\text { density } \\
\text { (g/100Kcal) }\end{array}$ & $\begin{array}{l}\text { Iron density } \\
\text { (mg/100Kcal }\end{array}$ & $\begin{array}{l}\text { Zinc density } \\
\text { (mg/100Kcal }\end{array}$ & $\begin{array}{l}\text { Vitamin C } \\
\text { density } \\
\text { (mg/100Kcal) }\end{array}$ & $\begin{array}{l}\text { Vitamin A } \\
\text { density } \\
\text { RAE/100Kcal)* }\end{array}$ & $\begin{array}{l}\text { Calcium density } \\
\text { (mg/100Kcal) }\end{array}$ \\
\hline $\begin{array}{l}\text { Tea without milk, } \\
\text { with sugar }\end{array}$ & 0.4 & 0.0 & 0.0 & 0.0 & 0.0 & 0.0 & 0.3 \\
\hline White Bread & 2.7 & 3.2 & 0.2 & 0.3 & 0.0 & 0.0 & 3.6 \\
\hline Rice boiled no Oil & 1.6 & 1.6 & 0.1 & 0.3 & 0.0 & 0.0 & 2.3 \\
\hline Fish Fresh Stew & 0.9 & 6.4 & 0.4 & 0.1 & 12.8 & 0.0 & 4.2 \\
\hline $\begin{array}{l}\text { Rice with Coconut } \\
\text { Milk }\end{array}$ & 1.7 & 1.7 & 0.6 & 0.5 & 0.0 & 0.0 & 5.1 \\
\hline $\begin{array}{l}\text { Small Dried fish } \\
\text { relish with coconut } \\
\text { milk }\end{array}$ & 2.6 & 4.6 & 0.2 & 0.3 & 1.4 & 0.0 & 91.3 \\
\hline $\begin{array}{l}\text { Maize and sorghum } \\
\text { stiff porridge }\end{array}$ & 1.1 & 2.7 & 1.2 & 0.5 & 0.0 & 0.0 & 26.6 \\
\hline $\begin{array}{l}\text { African doughnut / } \\
\text { bun }\end{array}$ & 3.2 & 1.6 & 0.1 & 0.1 & 0.0 & 0.0 & 2.4 \\
\hline $\begin{array}{l}\text { Potatoes, flesh only, } \\
\text { boiled, without/skin }\end{array}$ & 0.9 & 2.0 & 0.4 & 0.3 & 8.6 & 0.0 & 9.3 \\
\hline $\begin{array}{l}\text { Kidney bean relish } \\
\text { with coconut }\end{array}$ & 0.8 & 3.4 & 2.5 & 1.3 & 6.5 & 0.0 & 17.4 \\
\hline $\begin{array}{l}\text { Fish relish with } \\
\text { coconut milk }\end{array}$ & 1.4 & 8.5 & 0.7 & 0.8 & 1.7 & 0.0 & 197.0 \\
\hline $\begin{array}{l}\text { Maize porridge }+ \\
\text { margarine }+ \text { sugar }\end{array}$ & 1.0 & 1.1 & 0.4 & 0.2 & 0.0 & 0.0 & 0.9 \\
\hline $\begin{array}{l}\text { Sorghum porridge } \\
\text { with sugar }\end{array}$ & 0.9 & 1.1 & 0.4 & 0.2 & 0.0 & 0.0 & 3.0 \\
\hline $\begin{array}{l}\text { Milk whole, } 3.25 \% \\
\text { milk fat }\end{array}$ & 0.6 & 5.3 & 0.2 & 0.7 & 0.0 & 0.0 & 191.7 \\
\hline $\begin{array}{l}\text { Mix Flour Porridge } \\
\text { and Sugar }\end{array}$ & 1.3 & 1.7 & 0.4 & 0.2 & 0.0 & 0.0 & 24.9 \\
\hline Sweet potato, boiled & 1.0 & 2.2 & 0.8 & 0.5 & 12.4 & 0.0 & 8.2 \\
\hline Mixed fruit Juice & 0.5 & 1.6 & 0.4 & 0.2 & 58.0 & 0.0 & 36.9 \\
\hline Wheat Porridge & 0.2 & 7.0 & 0.5 & 0.5 & 0.0 & 0.0 & 8.0 \\
\hline $\begin{array}{l}\text { Cassava with } \\
\text { Coconut milk }\end{array}$ & 2.2 & 0.9 & 0.6 & 0.3 & 10.4 & 0.0 & 8.4 \\
\hline $\begin{array}{l}\text { Sweet potato leaves } \\
\text { relish }\end{array}$ & 1.7 & 2.2 & 1.5 & 0.4 & 23.5 & 0.0 & 66.0 \\
\hline Amaranth leaves & 0.9 & 1.4 & 1.0 & 0.4 & 15.9 & 68.8 & 90.3 \\
\hline
\end{tabular}

*Twenty one mostly consumed foods arranged according to frequency of consumption 


\section{Energy consumption}

Table 5 summarizes the energy (kcals) consumed in a 24hour period. Mean energy intake is categorized by age group and breastfeeding status of the children. In principle, according to ProPAN if 50\% (median) or more of the children meet the recommended level of energy, it is considered that all the sampled children met their ener- gy. In this survey, more than half $(58 \%)$ of the children consumed $100 \%$ or more of the median kilocalories recommended. However, segregating the children by breast feeding status, children who were not breast fed, fell short and only $37 \%$ met the recommended levels. This shows the importance of breast milk in complementing energy deficit.

Table 5: Proportion of children consuming 100\% or more of the median energy (kilocalories) recommendation

\begin{tabular}{lllll}
$\begin{array}{l}\text { Energy (age and } \\
\text { breastfeeding } \\
\text { category) }\end{array}$ & $\begin{array}{l}\text { Percent of children } \\
\text { who met the } \\
\text { recommendation }\end{array}$ & $\begin{array}{l}\text { Percent of children } \\
\text { who did not meet the } \\
\text { recommendation }\end{array}$ & $\begin{array}{l}\text { Mean } \\
\text { intake }\end{array}$ & SD \\
\hline Total & 58.0 & 42.0 & 642.4 & 495.6 \\
6-11 months & 63.4 & 36.6 & 450.9 & 335.5 \\
12-23 months & 55.0 & 45.0 & 747.8 & 537.4 \\
Breastfed & 61.3 & 38.7 & 627.4 & 488.8 \\
Non-breastfed & 37.0 & 63.0 & 738.7 & 537.1 \\
\hline
\end{tabular}

Energy consumed at meal times and meal frequency Table 6 shows the percentage of energy (kilocalories) consumed by children at main meal times (morning, afternoon, evening) and in-between meals (before the main morning meal, between the main morning and afternoon meals, between the main afternoon and evening meals, after the main evening meal). The contribution of snacks in terms of energy intake was very minimal compared to the main meals. This is further shown by median energy contribution, which has continuously recorded zero. These results imply that most of children aged 6-23 months were not given snacks between main meals. Examples of snacks included; ripe tomato, biscuits, buns, ripe banana and popcorn. Drinks consumed in between meals included sodas and tea. Therefore children obtained a substantial amount of energy from the main meals. 
Table 6: Percent of energy (kilocalories) consumed by children at main meal times

\begin{tabular}{|c|c|c|c|}
\hline Meal time & Category & Mean Energy intake (kcal) & Median Energy intake \\
\hline \multirow[t]{7}{*}{ Morning snacks before main meal } & Age group & & \\
\hline & All children (6-23) & 3.9 & 0 \\
\hline & $6-11$ & 4.9 & 0 \\
\hline & $12-23$ & 3.3 & 0 \\
\hline & Breast feeding status & & \\
\hline & Breast fed & 4.3 & 0 \\
\hline & Non breast fed & 1.7 & 0 \\
\hline \multirow[t]{7}{*}{ Main morning meal } & Age group & & \\
\hline & All children (6-23) & 21.5 & 15.7 \\
\hline & $6-11$ & 26.1 & 15.8 \\
\hline & $12-23$ & 19.0 & 15.7 \\
\hline & Breast feeding status & & \\
\hline & Breast fed & 21.8 & 15.2 \\
\hline & Non breast fed & 19.3 & 20.3 \\
\hline \multirow[t]{7}{*}{ Morning snacks After main meal } & Age group & & \\
\hline & All children (6-23) & 5.3 & 0.0 \\
\hline & $6-11$ & 3.9 & 0.0 \\
\hline & $12-23$ & 6.1 & 0.0 \\
\hline & Breast feeding status & & \\
\hline & Breast fed & 4.7 & 0.0 \\
\hline & Non breast fed & 9.8 & 0.0 \\
\hline \multirow[t]{6}{*}{ Main afternoon meal } & Age group & & \\
\hline & All children (6-23) & 32.9 & 33.4 \\
\hline & $6-11$ & 30.1 & 32.1 \\
\hline & $12-23$ & 34.3 & 34.2 \\
\hline & Breast feeding status & & \\
\hline & Breast fed & 33.2 & 33.7 \\
\hline Non breast fed & 30.9 & 29.4 & \\
\hline \multirow[t]{7}{*}{ Afternoon snacks After main meal } & Age group & & \\
\hline & All children (6-23) & 2.5 & 0 \\
\hline & $6-11$ & 1.4 & 0 \\
\hline & $12-23$ & 3.0 & 0 \\
\hline & Breast feeding stat & & \\
\hline & Breast fed & 2.5 & 0 \\
\hline & Non breast fed & 2.1 & 0 \\
\hline Main evening meal & All children (6-23) & 19.0 & 11.7 \\
\hline
\end{tabular}

The number of meal times (formal and informal combined) that children had in a 24 -hour period is shown in Table 7. The number of meals time ranged from 2.4 to 3.0. In general children received 2.7 meals in 24 hours with a median of 3.0 meals. The lowest number of meals (2.4) was given to children aged 6-11 months with a me- dian of 2 meals in 24 hour period. This also confirms that in between meals snacks were given to very few children. However, percent of children consuming the minimum recommended meal time frequency in a 24-hour period were all above $50 \%$ in all age groups as shown in Table 8. The most consumed foods and preparations for children 6-23 months 
Table 7: The number of meal times (formal and informal combined) that children had in a 24hour period

\begin{tabular}{llllll}
\hline Category of children & $\mathbf{N}$ & Mean & Variance & Std Dev & Median \\
\hline All children aged 6-23 months & 202 & 2.7 & 1.6 & 1.3 & 3.0 \\
Children aged 6-11 months & 71 & 2.4 & 1.7 & 1.3 & 2.0 \\
Children aged 11-23 months & 131 & 2.9 & 1.5 & 1.2 & 3.0 \\
Breastfed children & 175 & 2.7 & 1.6 & 1.2 & 3.0 \\
Non Breast fed children & 27 & 3.0 & 2.3 & 1.5 & 3.0 \\
\hline
\end{tabular}

Table 8: Percent of children ( 6 - 23 months) consuming the minimum recommended meal time frequency in a 24-hour period, stratified by age group

\begin{tabular}{|c|c|c|c|}
\hline Category of children & $\begin{array}{l}\text { Recommended number of } \\
\text { meals }\end{array}$ & $\mathbf{n}$ & $\%$ \\
\hline \multirow[t]{3}{*}{ All the children } & Not reached & 68 & 34 \\
\hline & Reached & 134 & 66 \\
\hline & Total & 202 & 100 \\
\hline \multirow[t]{3}{*}{ Children aged 6-11 months } & Not reached & 23 & 32.9 \\
\hline & Reached & 47 & 67.1 \\
\hline & Total & 70 & 100 \\
\hline \multirow[t]{3}{*}{ Children aged 11-23 months } & Not reached & 45 & 34.6 \\
\hline & Reached & 85 & 65.4 \\
\hline & Total & 130 & 100 \\
\hline
\end{tabular}

The most consumed foods and preparations for children aged 6-23 months in Zanzibar are shown in Figure 1. Mothers who were interviewed regarded tea as a beverage and refreshing drink that is also taken by most family members at any time desired. This tradition of taking tea might have emanated from the Arabs who settled in the Island and introduced this culture. Tea without milk but with sugar was the most consumed preparation by $65 \%$ of the respondents.

The next frequently consumed food by children was bread (commonly known as Tosi or Boflo), in most cases being consumed with the tea. In most areas of the Island normally tea was drank with bread. Rice boiled with no oil was the third in the hierarchy of foods given to children. This was often consumed with fresh fish stew and sardines. Fish and sardines were the common relish in Zanzibar and since the Island is surrounded by the Indian Ocean all over, fish and sardines are available and affordable to most households. Numerous fish species are landed from the ocean and sold to immediate customers. Since coconut milk is a common preferred condiment in meals prepared in the Islands, rice cooked with coconut milk was another meal frequently fed to children. Coconut milk is normally mixed in most stews and gravies. Other foods and preparations ranked by preference are as shown in Figure 1. 


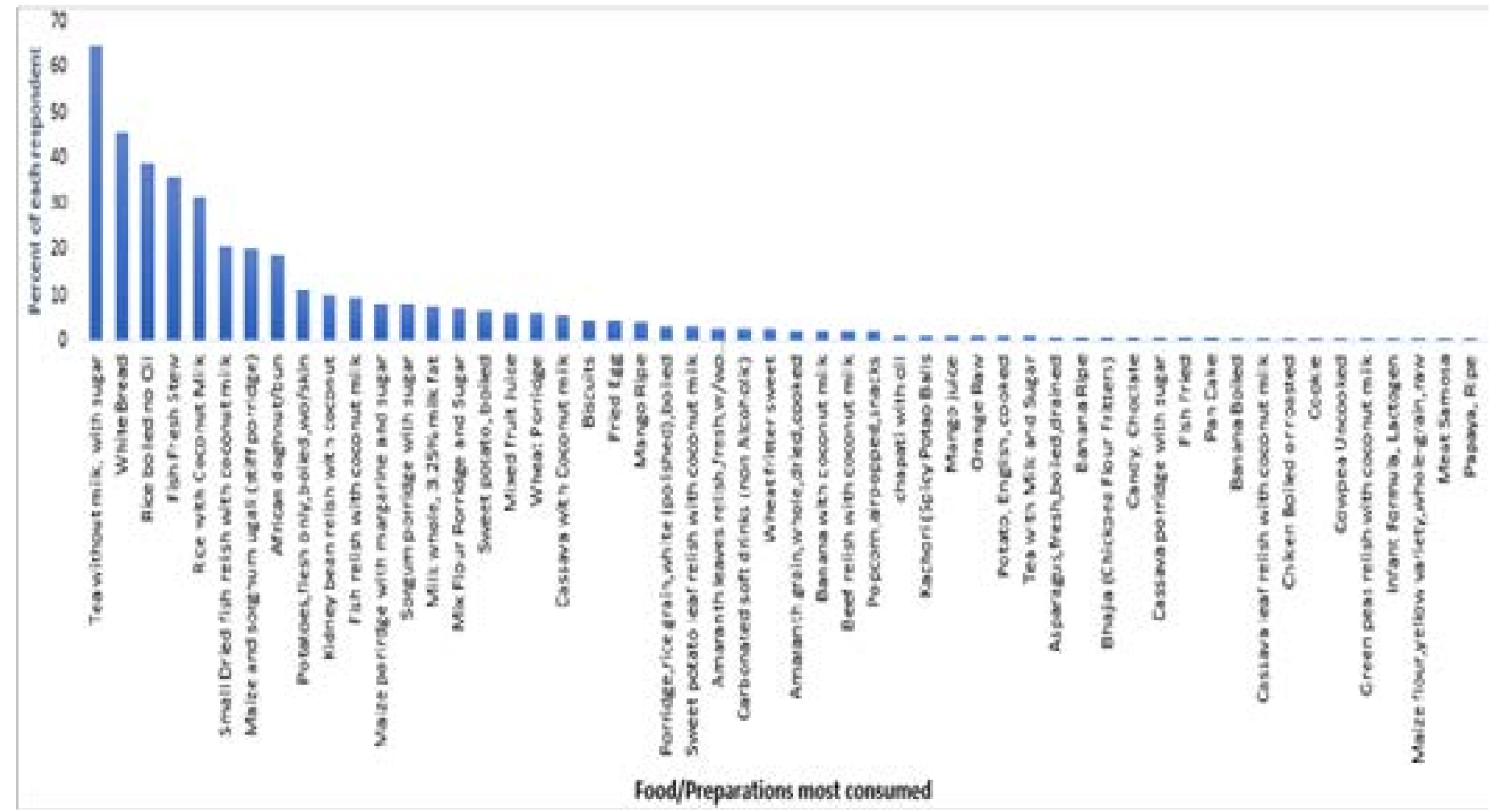

Figure 1: Most consumed foods and preparations for children 6-23 months in Zanzibar

\section{Nutrient Intake}

The children's diets were insufficient for all assessed micro nutrients. These included iron, zinc, vitamin A, and calcium (Table 9). The nutrients for which about half or more of the children were consuming 100 percent (or more) of their proxy recommendation were protein and vitamin $\mathrm{C}$ only. The worst situation was for iron and vitamin A. It is also imperative to note that ProPAN does not adjust requirements based on the quality of protein or bioavailability of nutrients, except for iron, so adequacy was probably lower because much of the nutrients consumed by the children were from plant-sources. 
Table 9: Results of the 24-hour recall analysis: Children who met recommended nutrient intakes and mean intakes

\begin{tabular}{|c|c|c|c|}
\hline Nutrient (and age category) & $\begin{array}{l}\text { Percent of children consuming } \\
100 \% \text { or more of the proxy } \\
\text { nutrient recommendation }\end{array}$ & Mean intake & SD \\
\hline \multicolumn{4}{|l|}{ Protein (g) } \\
\hline Total & 91 & 15.81 & 13.10 \\
\hline 6-11 months & 90.1 & 11.06 & 10.35 \\
\hline $12-23$ months & 91.5 & 18.43 & 13.73 \\
\hline \multicolumn{4}{|l|}{ Iron (mg) } \\
\hline Total & $0.5(15.5)^{*}$ & 2.35 & 2.51 \\
\hline 6-11 months & $1.4(2.8)^{*}$ & 1.74 & 2.39 \\
\hline $12-23$ months & $0.0(22.5)^{*}$ & 2.68 & 2.53 \\
\hline \multicolumn{4}{|l|}{ Zinc (mg) } \\
\hline Total & 8.5 & 2.11 & 1.78 \\
\hline 6-11 months & 7.0 & 1.48 & 1.41 \\
\hline $12-23$ months & 9.3 & 2.46 & 1.87 \\
\hline$\underset{\text { Total }}{\text { Vitamin } A(\mu g \text { RE })}$ & 0.5 & 1.88 & 11.41 \\
\hline 6-11 months & 0 & .0056 & 0.05 \\
\hline $12-23$ months & 0.8 & 2.91 & 14.12 \\
\hline \multicolumn{4}{|l|}{ Vitamin C (mg) } \\
\hline Total & 67.0 & 18.91 & 27.99 \\
\hline 6-11 months & 95.8 & 13.08 & 19.78 \\
\hline $12-23$ months & 51.2 & 22.13 & 31.23 \\
\hline \multicolumn{4}{|l|}{ Calcium (mg) } \\
\hline Total & 18.0 & 113.481 & 68.07 \\
\hline 6-11 months & 11.3 & 109.92 & 225.44 \\
\hline $12-23$ months & 21.7 & 115.44 & 126.93 \\
\hline
\end{tabular}

\section{Discussion}

This study sought to assess dietary adequacy in children below two years in Zanzibar. Mean energy and protein density of the diets were higher than minimum desired levels for children while mean iron and vitamin A were lower than the desired density from complementary foods. The most frequently consumed foods were tea and bread. About $86 \%$ of the children were breastfed showing that breastfeeding was a common practice in the studied population. Breastfeeding in Zanzibar is promoted even through Islam religion, which insists that the child should be breastfed up to two years of age, although families can even go beyond that age in case they prefer to do so. Due to the fact that this practice has been integrated with religion, most women and men adhere and make sure it happens. However, a practice which has never been observed very closely is the exclusive breastfeeding for six months. The timing of the introduction of complementary foods and drinks in addition to breast milk is very critical for child growth and development ${ }^{1,13,18}$. The predicaments for infants and young children are associated with "too early" and "too late introduction of complementary foods. 
According to WHO, ideal practice number 7 states that all infants are fed semi-solid complementary foods at 6 months of age (180 days)10. Our findings showed that mean age for introduction of complementary foods was 4 months (SD 1.8). Early initiation of complementary foods could probably be a contributing factor to higher rates of malnutrition in Zanzibar. Recent estimates of the prevalence of stunting and micronutrient deficiencies rank Africa as having amongst the highest rates in the world8. Young children are particularly vulnerable to under-nutrition given their high nutrient requirements for growth $^{19,20}$. Other studies done elsewhere showed that early initiation of complementary foods ranged from 2 to 4 months depending on several factors including geographical location and ethnic group ${ }^{21,22}$. Early introduction of complementary foods coupled with the serving of small meal sizes reflect inadequate nutrient intake. It was also observed that key nutrients such as iron, zinc and vitamin $\mathrm{A}$ from the diets consumed by children aged 11-23 months were not adequate. For instance, black tea, which was the most frequently consumed beverage by the children, also contains polyphenols that inhibit iron absorption $^{23,24}$. According to Hurrell and colleagues, certain polyphenols are able to form complexes with iron, which makes the complex-bound iron unavailable for absorption $^{24}$. Equally, since the diet was predominantly plant-based, supplying mostly pro-vitamin A carotenoids, which are known to have lower vitamin $\mathrm{A}$ activity than retinol from animal-source foods ${ }^{19}$, vitamin $A$ intake was likely to be low in the surveyed children. It is important to note that the cooking methods of the leafy vegetables may have led to very low vitamin $C$ content than what is recorded in the food composition tables since it is a heat labile nutrient ${ }^{25}$. Another study also reported similar findings that overall complementary feeding practices in Tanzania as measured by dietary diversity, meal frequency and acceptable diet were not adequately met $^{1}$.

The authors concluded that there was a need for interventions to improve the nutritional status of young children in Tanzania. The findings from this study indicated that the surveyed children consumed adequate energy. However, evidence from the literature indicated that even if children are getting enough energy, they could still be undernourished if they are not receiving enough of any of micronutrients such as vitamins and minerals ${ }^{1}$. This calls for a need to support nutrient supplementation among young children. Market surveys and 24 hour dietary recalls, showed that Zanzibar has got diverse varieties of foods, which were locally available and suitable for feeding children. Nevertheless, mothers/caregivers lack knowledge on how best they could combine locally available foods to create energy and nutrients dense diets. If attempts to improve the nutrient intake through diet diversification and improvement of the cooking and food preparation skills are not implemented, childhood malnutrition will continue to be a major concern in Zanzibar. This is an opportunity for intervening on the gaps that were observed in the whole process. In addition, it is recommended that interventions that will be developed should also involve men. Some men who were available during the survey showed interest in learning about ideal IYCF practices so that they could participate planning and implementation of feeding practices that will lead to improvement of nutritional status of children. Although some studies have found that women's discretionary income has greater impact on child nutrition and food security than men's ${ }^{26,27}$, in most cases the men have a final say with regard to resource allocation in the household. Hence involvement of men in all intended household interventions is of paramount importance. The importance of good child nutrition was also expressed by some community leaders. For example, a Sheha in one of the Shehias, where rice was the major crop produced, remarked that "child growth is similar to rice growing whereby at the early stage of the plant growth a lot of effort (in terms of time, inputs: fertilizers, weeding), has to be invested to ensure proper growth and ultimately good harvest'. Likewise, he insisted that parents are required to invest sufficient resources in terms of food and care to their children in order to have healthy productive and reproductive adults.

\section{Conclusion}

Infant and young child feeding in Zanzibar was sub-optimal. Children diets were limited in fruits and vegetables that caused micronutrient of nutritional importance such as iron, zinc and vitamin A to be supplied below recommended level. Equally, fat intake was below recommended level. Early initiation of complementary foods could be a contributing factor to higher rates of malnutrition in Zanzibar. Nutrition education on appropriate complementary foods should be given to caregivers. Promotion 
of consumption of diversified diets and locally available nutrient dense foods such as fish, fruits and vegetables should be emphasized so as to achieve adequate intake of nutrients to infants and young children.

\section{Acknowledgements}

The authors would like to acknowledge the financial assistance from the UNICEF, who facilitated the successful survey. The authors are thankful to the Revolutionary Government of Zanzibar for granting permission to conduct the survey. We are grateful to the Shehas of the various Shehias visited for their dedicated work and the mothers/caregivers for their willingness to participate in the study.

\section{Source of funding}

The authors would like to acknowledge the financial assistance from the UNICEF, Tanzania.

\section{Competing interests}

The authors declare that they have no competing interests.

\section{Authors' contributions}

$\mathrm{JK}, \mathrm{EM}$ and EC coordinated all research, participated in the data collection, data management, data analysis and drafted the manuscript. PM and JN coordinated all the data collection and data analysis. JP provided technical support at every stage of the process. AM, AN and RM participated in the data collection, computation of dietary intake and interpretation of findings. NB and KK participated in study design and methodology and helped to draft the manuscript. AS, JM and HA coordinated and prepared selected families in Zanzibar during data collection. All authors read and approved the final manuscript.

\section{Acknowledgements}

The authors acknowledge the financial assistance from UNICEF, Tanzania who facilitated the successful survey in Zanzibar. We are grateful to the research team for their dedicated work and the mothers for their willingness to participate in the study and to allow their infants to be test the developed recipes.

\section{References}

1. Victor R, Baines S, Agho K, Dibley M: Factors associated with inappropriate complementary feeding practices among children aged 6-23 months in Tanzania. Matern Child Nutr 2014, 10:545-561.

2. WHO: Infant and Young Child Feeding. In Fact Sheet number 342. WHO2010b.

3. WHO/UNICEF: Indicators for assessing infant and young child feeding practices Part 3 Country profiles. (WHO ed. pp. 81. Geneva, Switzerland 2010:81.

4. Moghaddam HT, Khademi G, Abbasi MA, Saeidi M: Infant and Young Child Feeding: a Key area to Improve Child Health. Pediatrics International 2015, 3:1057 - 1066.

5. Adair LS, Fall CHD, Osmond C, Stein AD, Martorell R, Ramirez-Zea M, Sachdev HS, Dahly DL, Bas I, Norris SA, et al: Associations of linear growth and relative weight gain during early life with adult health and human capital in countries of low and middle income: findings from five birth cohort studies. The Lancet, 382:525-534.

6. Agunbiade OM, Ogunleye OV: Constraints to exclusive breastfeeding practice among breastfeeding mothers in Southwest Nigeria: implications for scaling up. International Breastfeeding Journal 2012, 7:5.

7. Martorell R, Horta BL, Adair LS, Stein AD, Richter L, Fall CH, Bhargava SK, Biswas SK, Perez L, Barros FC, Victora CG: Weight gain in the first two years of life is an important predictor of schooling outcomes in pooled analyses from five birth cohorts from low- and middle-income countries. J Nutr 2010, 140:348-354.

8. BlackRE, Victora CG, Walker SP, Bhutta ZA, Christian P, de Onis M, Ezzati M, Grantham-McGregor S, Katz J, Martorell R, Uauy R: Maternal and child undernutrition and overweight in low-income and middle-income countries. The Lancet 2013, 382:427-451.

9. Victora CG, Adair L, Fall C, Hallal PC, Martorell R, Richter L, Sachdev HS: Maternal and child undernutrition: consequences for adult health and human capital. The Lancet 2008, 371:340-357.

10. WHO: Essential nutrition actions: improving maternal, newborn, infant and young child health and nutrition. World Health Organization 2013.

11. UNICEF: Progress for children: A report card on nutrition. Number 42006.

12. Grantham-McGregor S, Cheung YB, Cueto S, Glewwe P, Richter L, Strupp B: Developmental potential in the first 5 years for children in developing countries. The Lancet 2007, 369:60-70.

13. WHO/UNICEF: Complementary Feeding of Young Children in Developing Countries: A Review of Current Scientific Knowledge. (WHO ed. pp. 228. Geneva, Switzerland1998:228. 
14. PAHO: Guiding Principles for Complementary Feeding of the Breastfed Child. . Washington DC: Pan American Health Organization; 2004.

15. Kinabo JL, Mwanri AW, Mamiro PS, Kulwa K, NH B, Picado J, Msuya J, Ntwenya J, Nombo A, Mzimbiri R, et al: Infant and young child feeding practices on Unguja Island in Zanzibar, Tanzania: a ProPAN based analysis. Tanzania Journal of Health Research 2017, 19.

16. Lukmanji Z. HE, Mlingi N., Assey V., Ndossi G., Fawzi W: Tanzania food composition Tables. MUHASTFNC, HSPH, Dar es Salaam Tanzania 2008.

17. NICHD: Building Strong Bones: Calcium Information for Health Care Providers National Institute of Child Health and Human Development. In NIH Publication No 05-5305A https://www.nichd.nih.gov/publications/pubs/documents/NICHD_MM_HC_FS_rev.pdf Accessed on17.09.2014 2006.

18. Mamiro PS, Kolsteren P, Roberfroid D, Tatala S, Opsomer AS, Van Camp JH: Feeding practices and factors contributing to wasting, stunting, and iron-deficiency anaemia among 3-23-month old children in Kilosa district, rural Tanzania. J Health Popul Nutr 2005, 23:222-230. 19. Dewey KG, Brown KH: Update on technical issues concerning complementary feeding of young children in developing countries and implications for intervention programs. Food Nutr Bull 2003, 24:5-28.

20. Nkala TE, Msuya SE: Prevalence and predictors of exclusive breastfeeding among women in Kigoma region, Western Tanzania: a community based cross-sectional study. Int Breastfeed J 2011, 6:17.

21. Hussein AK: Breastfeeding and complementary feeding in Tanzania. East African Journal of Public Health 2005, $2: 27-32$.

22. Daelmans B, Mangasaryan N, Martines J, Saadeh R, Casanovas C, Arabi M: Strengthening actions to improve feeding of infants and young children 6 to 23 months of age: summary of a recent World Health Organization/ UNICEF technical meeting, Geneva, 6-9 October 2008. Food Nutr Bull 2009, 30:S236-238.

23. Hurrell RF: Fortification: overcoming technical and practical barriers. J Nutr 2002, 132:806s-812s.

24. HurrellRF, Reddy M, Cook JD: Inhibition of nonhaem iron absorption in man by polyphenolic-containing beverages. Br J Nutr 1999, 81:289-295.

25. Igwemar NC, Kolawole SA, Imran IA: Effect of Heating on Vitamina C Content of Some Selected Vegetables. International Journal of Scientific and Technology Research 2013, 2:209 - 212.

26. Smith LC, Usha R, Aida N, Lawrence H, Reynaldo M: The importance of Womens status for child nutrition for Developing Countries. In Research Report, vol. 131. Washington DC: IFPRI; 2003.

27. UNICEF: Gender influence on child survival, health and nutrition: A narrative review. 2011. 